\title{
ASPECTOS GENERALES DEL ESTADO, PARTIDOS E IGIESIA EN COLOMBIA
}

Joaquín H. Fontecha ${ }^{2}$

Universidad Santo Tomás - Bucaramanga

\section{Resumen}

El texto hace un abordaje al acontecer político de nuestra historia, y de las mutuas relaciones entre la Iglesia Católica y los partidos tradicionales en Colombia (liberal-conservador) en la configuración de los imaginarios políticos y religiosos de los colombianos como sustento de la violencia y la exclusión política.

\section{Palabras clave:}

Partidos políticos, política, Iglesia, Estado, poder, violencia.

\section{GENERAL ASPECTS OF STATE, POLITIGAL PARTIES AND GHURCH IN COLOMBIA}

\section{Albstract}

The text is about the political events related to our history and the mutual relations between the Catholic Church and the traditional political parties (Liberal and Conservative) in Colombia, becoming part of political and religious imaginary of Colombian peoples as support of violence and political exclusion.

\section{Key words:}

Parties, politics, Catholic Church, state, power, violence.

1 Este trabajo es el resultado parcial de la investigación sobre "Historia Política en Santander, referente al periodo comprendido entre 1900-1950.", en el marco de la Maestría en Historia del autor, en la Universidad Industrial de Santander.

2 Historiador, Universidad Estatal de Vorónezh, Rusia. Especialista en Teoría Métodos y Técnicas de Investigación Social, Universidad Industrial de Santander. Magíster en Historia, Universidad Industrial de Santander. 
En el proceso de formación del Estado Latinoamericano, ningún país desarrolló una etapa siquiera similar a lo que significó el despotismo para la consolidación y unificación de los estados nacionales. Los países iberoamericanos tuvieron que vivir este proceso en su etapa republicana en medio de una desarticulación regional que, a su vez, impide la formación de mercados y clases sociales nacionales y que en el plano político significa la garantía más expedita para el desarrollo de formaciones caudillistas y clientelistas ${ }^{1}$ en los espacios de poder y en el ámbito local, regional y nacional.

Este fenómeno le dio una característica al proceso de desarrollo de nuestros Estados nacionales como en el caso colombiano cuyo surgimiento estuvo cruzado por la polarización partidista mediante la movilización social y militar para las guerras y la legitimación de las conquistas del poder de cada partido en sus respectivas hegemonías, por lo menos de 1830 a 1958. Atengámonos ahora a lo que Safford afirma que "estos dos grupos antagónicos (...) Constituyeron las bases de los partidos (...) (Que) ya existían (...) en forma definida antes de la revolución del 40". (Guerra de los supremos) y lo que ésta hizo fue "(...) ahondar, hacer más fuertes las identidades de los partidos (...)."2 Todo esto parece confirmar que "(...) fue precisamente durante ese conflicto civil que los partidos cuajaron finalmente, con las características que iban a perdurar" 3 y reafirmar mediante la aceptación programática de 1848 y 1849 lo ya creado e inevitable: la declaración manifiesta de los dos partidos con mínimas diferencias doctrinarias. Este argumento corresponde muy bien a la postura de Bushnell quien clasificó como "proto-conservadores" al grueso del clero y a la flor y nata de la aristocracia santafereña y payanesa, mientras que los "santanderistas" eran más bien una baja oligarquía o especie de oligarquía emergente enfrentada a la alta oligar- quía de simpatías predominantemente bolivarianas ${ }^{4}$. Es necesario recalcar que estos orígenes hicieron que los partidos carecieran de estructura moderna o que no fueran partidos modernos de afiliados sino "sub-culturas diferenciadas pero complementarias que funcionaban a manera de federación de notables locales y de "electores llamados periódicamente a legitimar a estos notables". ${ }^{5}$ Es significativa la importancia que tiene "el sufragio universal masculino" de los años cincuenta decimonónicos, encadenado a la "dependencia económica, la sujeción política y la guerra" ${ }^{6}$ como mecanismo de adscripción de "matrícula ideológica" en una sociedad fragmentada en dos partidos (liberal y conservador) cuya estructura política se consolida mediante la pertenencia y lealtad a cada partido a la vez que diseminaba un "factor ideológico aglutinador, por vez primera, con cobertura nacional"7. Tales son algunos de los mecanismos de adscripción a cada partido: la herencia cultural transmitida de manera "biológica", los copartidarios, la clientela y las lealtades. Un corolario más en este proyecto son los intereses contradictorios de la elites dominantes o de sus facciones, que lograron integrarse desde arriba y fragmentar no sólo a éste sino escindir verticalmente la sociedad en dos sectores políticos canalizados por "los partidos a través de sus élites regionales" mientras "la legitimidad de las matrículas azul y roja del pueblo colombiano operaba simultáneamente, desde abajo como integrador"8. No es extraño, pues, que los partidos también cabe conjugarlos como estructuras para dirimir las tensiones de clase mediante la conformación poli-clasista ${ }^{9}$. Tenemos, en consecuencia, que la formación de los partidos liberal y conservador y su desarrollo posterior eran primordialmente un proyecto político de las elites en el que no existían intereses de los sectores sociales subalternos ${ }^{10}$.

Igualmente, la pugna por el control del Estado hizo que cada uno de los sectores 
políticos que llegaba al poder, buscara los mecanismos para perpetuarse en él. Esta tendencia se materializó en cada uno de los grandes periodos políticos en los cuales uno sólo de los partidos buscaba mantenerse en el poder con la exclusión del partido opositor. Radicalismo, Olimpo radical, Regeneración, República Liberal, Reacción Conservadora, son sólo ejemplos de este proceso que condujeron a la gestación de dos sub-culturas políticas excluyentes y a la generación de adhesiones, no en torno al Estado-nación sino a uno de los dos partidos políticos, que generaba tradiciones enfrentadas sobre la historia nacional, los mitos fundacionales y sobre el actuar político de las élites, lo que encontró expresión en los procesos educativos y en el tipo de representaciones que se privilegiaban respecto a la identidad nacional y al proyecto de Estado-nación.

Al proseguir con el tema, Marco Palacios, señaló unos antecedentes que son importantes para nuestro análisis en relación con el papel de los partidos en el proceso de unidad nacional. Planteó cómo la unidad partidista se convertiría en un factor de unidad nacional, como antecesora de la nación misma. Además, la actividad política se alimentaba de elementos regionales o localistas ${ }^{11}$. En este sentido, los partidos se consolidaron desde sus orígenes, mediante la utilización de mecanismos violentos y electorales que derrotaban al adversario y, de paso, adscribían a la población de manera partidista, proceso que en varias ocasiones intentaría repetirse durante el siglo $\mathrm{XX}^{12}$.

El precio de la construcción de una unidad nacional a partir de proyectos políticos sustentados e inmersos en estos mecanismos, arrojó como resultado un bipartidismo, que se mantuvo por más de siglo y medio con base en una competencia que ocasionó un "estado de guerra permanente", mediante la violencia "como instrumento para lograr sus afirmaciones y la adhesión y lealtad bipartidista del pueblo colombiano"13.

En Colombia se era liberal o conservador no por convicciones o por diferencias ideológicas sino por el odio y el deseo de retaliación sembrado en las "masas" del pueblo, que después de cada guerra y de cada combate quedaban matriculadas del lado del patrón y/o latifundista que los obligaba a formar parte de su ejército o contra el partido a que pertenecía la tropa que había asesinado a sus familiares.

Los mecanismos que adscribieron a la población a uno u otro partido, los ligaba a los conflictos políticos y religiosos del siglo XIX y al reclutamiento militar de las guerras civiles, contribuyeron a la formación de núcleos políticos locales que paulatinamente se polarizaban alrededor de personajes, intereses, programas y doctrinas, entre otros. Posteriormente, se convertirían en el "ideal nacional" de cada uno de ellos, anterior a la idea de pertenencia a una nacionalidad como tal, idea que se diluiría primero en intereses, ideologías y "culturas locales". Por ello, el proceso de formación del "sentimiento nacional", elemento fundamental que debería consolidar la legitimación del sistema institucional, apareció posterior a la consolidación del sentimiento partidista, pues éste tendría mucha vida e intensidad.

Los conflictos partidistas se gestaban alrededor de los problemas electorales y la competencia por el fortín burocrático, en los que el señalamiento religioso sobre el carácter de los liberales era un arma moral o teológica que descalificaba al contrario. Ninguno de los adversarios pondría en juego un proyecto que permitiera trazar un perfil político a partir de programas e ideas. Sería un simple juego de acciones y reacciones alrededor de pequeños intereses interpretados por los caudillos o por el clero provinciano, en torno a los cuales movilizarían a la población siempre con el objetivo de confrontar 
con el otro partido. Parece perfectamente claro que el Estado de Santander se había constituido en el bastión liberal más importante del nororiente colombiano $y$, a su vez, era considerado el enclave liberal más peligroso para el proyecto de centralización política. Mientras Boyacá en el oriente y Antioquia en el occidente conformarían el eje político-militar de la Regeneración y de la fundación de la república conservadora.

\section{LAS ELECCIONES}

Examinemos brevemente, que desde la fundación la República, las elecciones siempre jugaron un destacadísimo papel en la legitimación de los gobiernos, por cuanto éstas siempre se constituyeron en el método de transferencia del poder en Colombia. Desde 1830, presidentes y congresistas, así como miembros de los concejos municipales y diputados en las asambleas de provincia serían elegidos regularmente a través de un sufragio restringido ${ }^{14}$. Hay que reconocer que Colombia es un país eleccionario por excelencia y los comicios fueron inevitables; se constituyeron de acuerdo a la idiosincrasia de los pueblos o de las regiones en una fiesta, en un ritual, o en un duelo y permitieron la gobernabilidad en el país por más de 150 años de vida republicana con excepciones muy transitorias. Naturalmente, que ningún partido o facción lograría establecer una hegemonía duradera o cerrada sin acudir a las elecciones. Por ello, los gobernantes acudieron a la realización de los comicios y buscaron afanosamente la participación de la oposición en las elecciones sin importar si existían las mínimas garantías electorales y, si en caso que la oposición no asistiera, o, se abstuviera de participar en el debate comicial, se fundase desde el establecimiento otra, aunque fuera de nombre, (esta estrategia persiste aún). El triunfo en los comicios requería del reconocimiento por parte del perdedor; este hecho legitimaba el evento electoral por cuanto contaba con la participación de la oposición ${ }^{15}$.

En la historia comicial del país, se puede evidenciar una presencia constante de calendarios electorales que dinamizaba o diezmaba el agite político, gracias a la conducta que asumían los candidatos en disputa, sus agentes electorales y sus seguidores condicionarían constantemente la inestabilidad del orden público.

A su vez, estos conflictos originados aparentemente por las disputas entre los partidos tenían incidencia directa en la división de familias completas. Manuel Serrano Blanco manifestaría que "inclusive viejos lazos de amistad se destruían como consecuencia de las elecciones". Si bien es cierto, que las elecciones jugarían un enorme papel en la conformación de la nación, especialmente en Latinoamérica, el derecho del voto sería restringido hasta bien avanzado el siglo XX. Por otra parte, no se puede desconocer que las elecciones eran el pretexto para acudir a la agresión verbal y física entre los candidatos, los seguidores y los simpatizantes. Los electores, eran los llamados a tomar las decisiones más transcendentales para la patria y la nación. Sin embargo, en el contexto electoral sobresaldría la pugna violenta que implementaba la precariedad en el orden público durante las épocas electorales como lo denunciaban los periódicos de la oposición independiente del partido que controlaría el poder "de que el gobierno tiene el propósito de asesinar liberales con cualquier pretexto el día de las elecciones"16.

Lo que sí parece caracterizar la experiencia eleccionaria en Colombia es la simbiosis y sobrevivencia entre elecciones y violencia. La lucha partidista se prolongaba en los actos pre y post electorales. Los conflictos surgidos en torno al acto comicial, por lo general, se dirimían por la vía violenta, ya que el escrutinio y las sospechas de fraude no satisfacían a una de la partes en contienda. La hostilidad 
del electorado se mantenía durante y después del proceso de escrutinio de los votos. La natural expectativa de los resultados e inclusive el ánimo triunfalista o el espíritu de venganza entre quienes anticiparan la derrota motivaban a menudo actos de violencia.

Un corolario más, dentro del proceso electoral, era la posibilidad de transferencia del poder. Además, de los intereses en la contienda eleccionaria de quienes mantendrían el poder como los presidentes, gobernadores, alcaldes y otros, condujo a la fragilidad de las autoridades. Éstas, trataban de utilizar sus posiciones de influencia para manipular el proceso y, algunas veces, promovían personalmente los disturbios. La violencia en sentido estricto consistía principalmente en el uso de medidas de fuerza para que los opositores no concurrieran a las urnas. Y, como era natural, la misma posibilidad de fraude o violencia oficiales servía, a veces, como elemento disuasivo para que los grupos opositores se abstuvieran de participar, para no exponerse a peligros graves. Por lo menos, en el siglo XIX, no se asesinaba a candidatos presidenciales, aunque no faltarían agresiones entre excitados partidarios.

Son diversos los cuestionamientos que se le hacían a la autoridad durante las elecciones: primero, si el proceso era empañado por el fraude $y$, segundo, si las reglas del juego no eran consideradas igualmente justas por las partes en disputa. La falta de acuerdo sobre las reglas del juego que condicionaban la aceptación del sistema fue una fuente repetida de conflicto. La guerra de los Mil Días, a fines del siglo XIX, fue precedida por la intensa campaña electoral de 1898 y por un frustrado debate de reforma electoral en el Congreso.

Es sintomático que las irregularidades en las urnas teñirían el proceso de ilegalidad. La carencia de un sistema electoral moderno tampoco contribuía a crear un ambiente de confianza en las elecciones. No obstante que los niveles de legitimidad los proporcionaba la aceptación de los resultados por parte de los derrotados y su continua participación en las elecciones conferían cierto grado de legalidad a los victoriosos. Por su misma naturaleza, la prueba del fraude es sumamente vaga y las denuncias de fraude se utilizan como arma política por todos los partidos en disputa. Pero éste, sin embargo, es una consecuencia de un sistema electoral endeble e incapaz de garantizar la pureza del sufragio.

Aquí vale la pena hacer una pequeña digresión sobre el contexto político nacional caracterizado para la época por el dominio hegemónico del Partido Conservador (1885-1930) el cual, a toda costa, se impondría en las elecciones, con la intervención decisiva del clero y por medios ya corrientes como el fraude. El resto lo harían mecánicamente los denominados "caudillos", "caciques", "gamonales" 17. Ya que el poder se organizaba piramidalmente de modo tal que cada caudillo "de base" ó "puntero" se conectaba con otro u otros de rango superior, con los cuales formaba una estructura de dominación articulada mediante el intercambio de "favores" recíprocos. En su cima se encontraba siempre un referente "influyente" de nivel nacional que necesitaba de estas figuras menores para controlar las autonomías de ciertos grupos sociales a fin de facilitar su entramado clientelista en tiempo de elecciones.

En estas condiciones, no es mera coincidencia la presencia de nuevos fenómenos: el ascenso de los movimientos sociales, acelerados procesos de urbanización, la naciente industrialización, el desplazamiento de la mano de obra ocasionado principalmente por la violencia bipartidista y de inversión masiva en las obras públicas y el auge de las exportaciones cafeteras, provocaron reacomodamientos y nuevas alianzas 
en los bloques regionales de poder, así como nuevas contradicciones surgidas de intereses económicos y políticos de acuerdo con las nuevas circunstancias. Análogamente, emergía la rampante corrupción en amplios sectores de la burocracia, tolerada por las altas esferas del gobierno. Este fenómeno, contribuyó a acelerar el proceso de desprestigio del Partido Conservador. Dentro de este marco ha de considerarse la urgente necesidad de renovar los cuadros de las élites con miras a confrontar las nuevas realidades políticas ante lo planteado por la profunda crisis económica, conocida como la "gran depresión" y la necesidad de renovar las instituciones y el engranaje del Estado.

\section{PARTIDOS E IGLESIA}

Es interesante examinar también el problema desde las relaciones entre la Iglesia y los partidos políticos en el proceso de consolidación del Estado nacional. En Colombia, como legado de la presencia española en la conquista y la colonia, la construcción del Estado estuvo marcada por la fuerte presencia de la Iglesia que se mantuvo luego de la emancipación, a lo que habría que agregar la presencia en el poder de los dos partidos tradicionales que, a partir de la segunda mitad del siglo XIX, caracterizaron buena parte de la dinámica del Estado colombiano.

Así mismo, la Iglesia Católica era un protagonista político de primer plano en la historia nacional e históricamente, canalizaría la participación política de la población que configuraría el entramado cultural mediante los procesos de adscripción sobre los cuales descansaba el conflicto político colombiano; absorbía y subordinaba a otras instancias de la sociedad civil y predeterminaba los desarrollos del Estado. En este contexto, la Iglesia acumulaba una gran experiencia, ya que en ella reposaba la sostenibilidad del Estado Colonial y, desde luego, el Estado Nacional.
De igual modo, se convirtió en el apoyo indispensable para la consolidación del Estado español y para la expansión de los imperios coloniales europeos, ligándose de manera inseparable a los orígenes de los Estados iberoamericanos. La Iglesia, por ser una institución más articulada y organizada que el Estado, anterior a la existencia y a la unidad del Estado Nacional mismo y de los partidos políticos, durante varios siglos asumió la organización territorial y ejercía funciones fundamentales para la consolidación del Estado. El Estado republicano heredó y conservó sin mayores modificaciones el principio del "Patronato de Indias"18. Por ello, el naciente Estado republicano asumió la responsabilidad de la manutención del clero así como su intervención en la asignación de los cargos, privilegio contraído de manera exclusiva por la monarquía española durante la Colonia.

Naturalmente, lo que nos interesa aquí no es tanto el poder de las parroquias y de las comunidades religiosas sino su relación directa con los círculos que ostentaban el poder económico y político en las diversas regiones, ya que la organización eclesiástica estaba ligada al poder (central) institucional $^{19}$. A diferencia de las sociedades europeas modernas, en nuestro proceso histórico se instauran instituciones inseparables y complementarias. Si bien, la Iglesia era la fuerza social más sólida en la integración del Estado, a su vez, representaba un orden social, expresaba los intereses de sectores sociales dominantes no necesariamente nacionales que se expresaban y reproducían en la sociedad colombiana y, por consiguiente, la Iglesia se presentaba como un poder autónomo pero supeditada al poder de los partidos y el Estado; sin desconocer la capacidad de intermediación en formación social. Aunque, a la Iglesia, también, se le atribuían las deformaciones del Estado, luego de la Independencia, al desconocer la responsabilidad de las élites, las fuerzas sociales y los partidos, que integraron dicho Estado ${ }^{20}$. 
De estas circunstancias nació el hecho que uno de los fenómenos más importantes para resaltar en el escenario de la política local, regional y nacional es el polo de poder que emanaba de la parroquia y que, en sí mismo, era un poder autónomo que le competía al poder civil, se constituía en uno de los tentáculos fundamentales de la legitimación ideológica del Estado, especialmente, en Colombia y particularmente en Santander. También, es necesario recalcar que, los partidos políticos, jugaban un papel trascendental en la cosmovisión de un microcosmos en el que el funcionamiento de lo institucional estaba mediado por el ejercicio de un poder local paralelo que supeditaba los propósitos, los intereses y los programas del Estado a intereses particulares y privados. Es así como en el ámbito local, por esta vía, los partidos llegaron a ejercer un poder que en determinados momentos podría rebasar al Estado y suplantaría sus funciones en el campo político, administrativo, judicial, e incluso en lo policivo y militar, como sucedía con las "policías cívicas" en Santander en los años treinta, y muchas otras prácticas que aún persisten en la vida política colombiana. El control de la burocracia municipal se convertía en un factor determinante para el ejercicio hegemónico del poder; los nexos de estas burocracias no se agotarían en el municipio sino que se articulaban en el ámbito departamental y nacional, no solamente a través de mecanismos administrativos del Estado sino principalmente por medio de canales partidarios, donde se encontraba realmente el nivel de la toma de decisiones.

Análogamente, el control burocrático se realizaba mediante el intercambio de favores, los cuales poseían curiosas derivaciones. Por ejemplo, cuando los partidos políticos competían entre sí, sus máximos líderes podrían necesitar el "favor" o apoyo de los "caudillos" regionales o provinciales de menor rango si se viesen en la necesidad de asegurarse cierto tipo de control regional, en cuyo caso el poder del caudillo adquiría importancia y devenía en un personaje funcional; este intercambio de "favores" poseía determinados códigos. Por ejemplo, un "favor" nunca podría ser denegado sin mengua del "honor" de quien lo pidiere. Por ello, los "caudillos" o líderes regionales jamás pedían favores más allá de lo razonable porque no se debía hacer "quedar mal" a la persona a quien se le formulaba el pedido. A cambio de ello, el poder superior le garantizaba conservación de cierta autonomía de control político local aún después de haberse producido un cambio en los cuadros superiores de la estructura partidista que, por lo general, obedecía a dominaciones caudillísticas. A pesar de que el poder del "caudillo" regional de menor rango estaba condicionado por el poder de otro "caudillo" de orden superior, su continuidad se explica porque cumplía eficazmente el papel de impedir las demandas de los grupos sociales que, si fueran excesivas, el "caudillo" no podría cumplir. La base de esta relación fue, por cierto, la "amistad", el parentesco o la familia, auspiciada por la garantía que propiciaba la parroquia.

Bien pareciera, por todo lo anterior, que la parroquia jugaba un papel protagónico en la vida local de los pueblos santandereanos y la sociedad, en general, hasta la promulgación de la Constitución de 1991 y, por ende, no se podía desconocer el rol histórico de la Iglesia en la formación del entramado cultural de la nación y la nacionalidad colombianas. Así como sus aportes a la conformación de los imaginarios, identidades e ideologías que trazaban el horizonte del accionar político durante las primeras décadas del siglo $X X$ y se deben mirar desde su contexto y su evolución histórica, ya que los grandes conflictos decimonónicos en Colombia obedecían en gran parte a la posición de los partidos políticos con respecto a la Iglesia.

En la segunda mitad del siglo XIX en Colombia, los partidos políticos (liberal y 
conservador) en su disputa por el poder y el control del Estado trazaron su frontera divisoria al tener como referencia su particular posición frente a la Iglesia Católica y en esta toma de partido, la jerarquía eclesial se colocaba más cerca de los conservadores, lo cual llevó a que los conflictos políticos se asociaran frecuentemente con los religiosos y se prolongarían en las definiciones político-doctrinarias durante el siglo XIX e incluso en el siglo XX, y se constituyeron en el principal elemento de identidad partidaria.

Adviértase que, a pesar de todo, el Partido Conservador se consolidaba a partir del aglutinamiento de núcleos políticos contestatarios de la postura anticlerical de los radicales en el siglo XIX. Acciones como la desamortización de bienes de manos muertas, la expulsión de los Jesuitas, la propuesta de un Estado laico, todo ello atentatorio contra los privilegios eclesiásticos, alentó más de una guerra civil en el siglo XIX. A raíz de las reformas implementadas en los años treinta del siglo $X X$, se revivieron en una nueva versión, la lucha religiosa del siglo XIX, pero con la suficiente fuerza para convertirse nuevamente en el centro del conflicto y en bandera política para la derrota de la República Liberal. Esta situación consolidó la alianza estratégica entre el partido conservador y la Iglesia, impuesta al Estado por dicho partido en la misma Constitución Nacional de 1886 y a través del Concordato ${ }^{21}$.

Un corolario más, lo constituyó la ofensiva católica del pensamiento integristarestauracionista europeo de finales del siglo XIX que tuvo una influencia directa en los pensadores y divulgadores no sólo a través del Partido Conservador sino de la misma Iglesia. Esta tradición continuó durante el siglo $X X$ con la permanente llegada de sacerdotes nacionalistas españoles, profundamente sectarios y excluyentes, que tuvieron ascendencia sobre la población campesina y que en los años treinta activaron la conformación de organizaciones de corte falangista.

Desde la época colonial, la Iglesia se había convertido en la división político administrativa más importante que la jurisdicción civil y, desde entonces, asumiría responsabilidades típicas del Estado ${ }^{22}$. De estas circunstancias nació el hecho de que durante siglos, por ejemplo, se convirtiera en el organismo más inmediato de regulación y mediación en los conflictos y litigios entre las gentes y ejerciera la función policiva y judicial para la convivencia cotidiana. Siempre la Iglesia tuvo el control de la Fe de bautizo y el Registro Civil de los colombianos, documentos indispensables que identificaban al colombiano y además le daban el derecho a ejercer el voto como lo evidencia el texto siguiente:

“Certificaciones que con formalidades legales expidan párrocos insertando las actas ó partidas de nacimiento existentes en los libros parroquiales, deben admitirse y tenerse como pruebas principales del estado civil al tenor en lo dispuesto en la Ley 57 de 1887. (...) las copias de las partidas de nacimiento que expidan los curas párrocos para los efectos electorales, pueden ir en papel común al tenor de lo dispuesto en el artículo 297 de la ley 85 de 1916 y sin estampillas de ninguna clase, pues, si la citada ley 85 de 1916 eximió de presentar en papel sellado tales copias para facilitar al ciudadano sus reclamaciones en asuntos electorales." 23

Al no existir registros diferentes a los eclesiásticos en lo que a nacimientos, matrimonios y defunciones se refería. Estos documentos adquirieron plena legitimidad ante el Estado en lo relacionado a la identificación del individuo. Por otra parte, la sociabilidad política en las divisiones territoriales en gran parte estaba regulada por actividades religiosas y supeditadas a las necesidades de la liturgia y el sermón 
sería el principal canal de comunicación con la población, y la ceremonia religiosa permitía concentrar la población urbana y rural, además, sin distingo de partido político, sexo y edad. Ya que los medios de comunicación masiva se limitaban a algún periódico que circulaba en la cabecera de la provincia. La función moral del párroco permitía un control total sobre los individuos, en su vida pública y privada ${ }^{24}$.

Se trata, desde luego, de tener en cuenta algunos aspectos que proporcionan una idea de la incidencia de la Iglesia hasta la primera mitad del siglo $\mathrm{XX}$, en la vida civil de los colombianos, carente de una vocación empresarial, con excepción de Antioquia o del Valle del Cauca. El párroco era una de las figuras de mayor brillo y su influencia solía ser mayor que la del alcalde. Su labor tuvo más continuidad y permanencia, era un profesional de su oficio, mientras el alcalde sólo una persona cuya experiencia y capacidad nada tenía que ver con su nombramiento.

Es posible concluir que la formación de los Estados nacionales en América Latina, fue un proceso tardío que se dio gracias a la intermediación de la Iglesia Católica, la cual fue el soporte ideológico y político del proceso de conquista y colonización en América. Sin embargo, el estado colombiano se caracteriza por sus propias peculiaridades, por cuanto sus referentes fundacionales fueron moldeados por los partidos tradicionales (Conservador-Liberal) que marcaron la vida y la identidad de los colombianos por más de 150 años. Este proceso estuvo signado por la participación activa de la Iglesia Católica, la cual, desde luego, contribuyó de manera significativa en la formación de los imaginarios que configuraron la Nación y el Estado colombiano. La Iglesia, fue testigo fiel de los aciertos y desaciertos de las decisiones políticas que tomaron los dirigentes políticos y que influyeron en la conformación del Estado nacional.

\section{REFERENCIAS}

SAFFORD, Frank. Aspectos sociales de la política de la Nueva Granada, 1825-1850. En: Aspectos sociales del siglo XIX en Colombia. Bogotá. s. n. 1977

BUSHNELL, David. Política y partidos en el Siglo XIX: Algunos antecédenos históricos. En: Sánchez G. y Peñaranda R. Pasado y presente de la violencia en Colombia. Bogotá: cerec, 1991

GUILLÉN MARTÍNEZ, Fernando. El Poder Político en Colombia. Punta de lanza. Bogotá. 1979

LEAL BUITRAGO, Francisco. Estado y política en Colombia. Siglo XXI. Bogotá. 1984

PALACIOS, Marco. "La fragmentación regional de las clases dominantes en Colombia: una perspectiva histórica", en Extensión Cultural, Universidad Nacional, 'Medellín, No. 8, 1980

CDIHR.-UIS. LA VANGUARDIA LIBERAL, Febrero 22 de 1922. p. 1

MOLINA, Gerardo. Las ideas liberales en Colombia, t. 2 Bogotá, Tercer Mundo, $8^{\mathrm{a}}$ Edición

REGISTRADURÍA NACIONAL DEL ESTADO CIVIL, Historia Electoral Colombiana, Bogotá, Regional. 1988.

EL TRABAJO CUENTA CON EL SUFICIENTE SOPORTE BIBLIOGRÁFICO, por cuanto está soportado con fuentes primarias y secundarias.

1 Los líderes políticos han utilizado al aparato estatal como una maquinaria destinada a satisfacer compromisos para-políticos o personales y en donde la discrecionalidad frente a la administración de lo público parece ser la regla más que la excepción. El clientelismo, en forma análoga, aparece como la manifestación más frecuente y deplorable, que acelera aún más la espiral de descrédito del esquema democrático de representación. El clima subyacente presentado es la sospecha. De esta manera, los líderes políticos, o todos aquellos que asumen como propia la actividad política, yacen de un modo permanente ante la opinión pública en el banquillo de los acusados: desde el más profundo escepticismo se alude a ellos como protagonistas activos o en potencia de los más graves niveles de corrupción institucional. Desde este punto de vista, el clientelismo político irrumpe como una consecuencia de la irresponsabilidad y los intereses egoístas de los líderes políticos, más que como una grave anomalía social.

2 SAFFORD, Frank. Aspectos sociales de la política de la Nueva Granada, 1825-1850. En: Aspectos sociales del siglo XIX en Colombia. Bogotá. s. n. 1977.158 p.

3 lbíd. SAFFORD, Op. Cit. 78-79 p.

4 BUSHNELL, David. Política y partidos en el Siglo XIX: Algunos antecédenos históricos. En: Sánchez G. y Peñaranda R. Pasado y presente de la violencia en Colombia. Bogotá: Cerec, 1991. pp. 76-77

5 GILHODES, Pierre. Modernidad, Democracia y partidos políticos. Bogotá: FESCOL, 1993. pp. 83 y 93. Esta estructura política llegó por lo menos hasta la mitad del siglo XX.

6 Según Leal Buitrago: "las lealtades personales no tuvieron su origen en identidades de clase social, sino que se manifestaron incondicionalmente, y con mucho interés material visible, como deberes de copartidario". LEAL BUITRAGO, Francisco. Estado y política en Colombia. SigloXXI. Bogotá. 1984. 137 p. Este argumento corresponde muy bien a lo que SAFFORD sostiene: "desde el año 1840 ser liberal o conservador en la mayoría de los casos era cuestión de herencia. Las familias criaron a sus hijos con identidad partidaria". SAFFORD. Op. Cit., p 158. Sobre la población rural, que era la mayoría, es necesario tener en cuenta la dependencia económica y la sujeción política que sobre ellos ejercían los terratenientes. En consecuencia, según GILHODES, “ser liberal o ser conservador fue vivir en un feudo liberal o conservador, ser hijo de liberal o de conservador, tener como fuente de trabajo un patrón 
liberal o conservador, ser enlistado bajo una bandera roja o azul y, tal vez, sobre todo, odiar al otro". GILLHODES, Pierre. Op. Cit. 80 P. Para el caso de Santander la mayoría de estas características son vigentes aún, sólo para que la guerra bipartidista no existe al ser controlada por el Estado, junto con el progreso en la concientización partidista que tiende a deslegitimar la tradición política.

7 LEAL BUITRAGO, Op. Cit., 93 p. De esta forma los partidos eran "la columna vertebral" del proceso de formación de la nacionalidad colombiana en el siglo XIX.

8 Ibíd. p.129

9 En este sentido, la separación que hace Colmenares entre terratenientes conservadores y burguesía naciente liberal ha sido discutida y aunque existiera esta diferencia, no cubría la totalidad de los partidos, en tanto que era parcial dentro de la clase dominante. Citado por SAFFORD, F. Op. Cit., p.165.

10 Según KONIG, los únicos que sí tenían conciencia de clase -dentro de las clases bajas- eran los artesanos de las sociedades democráticas y que intentaron imponer su propio proyecto político "que no se originó en las élites y que parecía ser más apropiado para la integración nacional y social de la Nueva Granada. KONIG, Hans Joachim, En el camino hacia la nación: nacionalismo en el proceso de formación del Estado y de la nación en la Nueva Granada, 1750 -1856. Bogotá: Banco de la República, 1994. 501 P. para más detalles y véase desde la página 460. Igualmente, BUSHNELL afirma que "el estamento artesanal urbano era más concientizado políticamente". Op. Cit. p.79 Al respecto, KALMANOVITZ afirma que no alcanzó "el nivel de gremio". En: Economía y Nación. Una breve historia de Colombia. Bogotá. Siglo XXI. 1988. 120 p.

11 PALACIOS, Marco. "La fragmentación regional de las clases dominantes en Colombia: una perspectiva histórica", en Extensión Cultural, Universidad Nacional, Medellín, No. 8, 1980, 287 p.

12 Esta tesis, aunque ha sido argumentada inmemorialmente, fue esbozada en 1972 por P. GILHODES, y algunos autores como Gonzalo SÁNCHEZ han hecho referencia a ella. No obstante, sólo se desarrolla de alguna forma en el trabajo de Apolinar DÍAZCALLEJAS, "Tesis sobre la Violencia en el nacimiento, afirmación y presencia del Partido Liberal y el Partido Conservador". Ponencia presentada al I Simposio Nacional sobre la violencia en Colombia: UPTC, Chiquinquirá, 1982.

13 DÍAZ CALLEJAS, Apolinar. Op. Cit., p.7

14 En la historia del país se han sucedido varios modelos básicos de conducta electoral. El primero de ellos, que adoptó el Congreso de Cúcuta para la Gran Colombia y siguió vigente hasta la Constitución de 1853, fue el sistema de elecciones indirectas por sufragio limitado. El sufragio universal de varones se conservó bajo la subsiguiente Constitución de 1858, de corte cuasi-federal, pero en la época del federalismo pleno (1863-85) hubo una descentralización total del sistema electoral, que permitió a los Estados soberanos organizar las elecciones de la manera que más les gustara; y mientras algunos reafirmaron el sufragio democrático, por lo menos en lo que al hombre se refería, otros volvieron a restringirlo. Por la Constitución de 1886 , tal como la diseñaron en un principio Núñez y Caro, se restableció en el ámbito nacional un sufragio indirecto y con requisitos económicos o de alfabetismo, como en los primeros tiempos, aunque sólo para las elecciones de presidente y congresistas. Así continuaron las cosas hasta ya entrado el siglo veinte, cuando se acogió nuevamente desde 1910 el voto directo, y cuando el sufragio se universalizó definitivamente en 1936 para los hombres y en 1954 para las mujeres.

15 Reconocemos, de una vez, que en estas observaciones hablamos de elecciones en su conjunto y no de lo que sucede en cada aldea del país.

16 CDIHR.-UIS. La Vanguardia Liberal, Febrero 22 de 1922. p.1 Alejandro Galvis Galvis denunciaba en su periódico, amenazas contra el directorio liberal le Santander.
17 MOLINA, Gerardo. Las ideas liberales en Colombia, t. 2 Bogotá, Tercer Mundo, 8 a Edición.

18 De manera que en el Patronato, el Estado Español daba los nombres de los prelados que el Papa debía nombrar, designaba los curas párrocos, percibía los diezmos eclesiásticos, autorizaba la fundación de Iglesias y la demarcación de diócesis y parroquias y pagaba a prelados y curas, los cuales, por la procedencia de su nombramiento, por las leyes vigentes y por el origen de su estipendio, eran prácticamente funcionarios estatales con un cierto grado de subordinación. En el período colonial la Iglesia Católica monopolizaba la enseñanza (...). Al producirse la emancipación, las autoridades republicanas, como sucesoras del poder de los Reyes de España, reivindicaron el ejercicio del Patronato. La Santa Sede implícitamente autorizó esta situación y entre los hombres públicos de la Nueva Granada prácticamente hubo unanimidad sobre el ejercicio de esta prerrogativa estatal, hasta mediados del siglo XIX, cuando ya en pleno funcionamiento de los partidos, el "problema religioso" se convirtió en elemento de diferenciación y en asunto de manipulación.

19 GILHODES, Pierre. Escribió al respecto: “(...) En la Nueva Granada colonial había sólo dos poderes que se expandían sobre toda la superficie de un territorio mal dirigido: el de la Iglesia y el de los propietarios hacendados, los encomenderos, poderes por otra parte complementarios. En la mayor parte del territorio colombiano esta situación no cambió con la independencia y (...) el Concordato firmado con la Santa Sede dejaba a discreción de las misiones católicas las dos terceras partes del territorio nacional. Por esto, el Estado está allí prácticamente ausente". Pierre GILHODES, “La estructuración traumatizante del poder del Estado: el caso Colombiano", Ponencia presentada al I Simposio Nacional sobre la Violencia en Colombia. UPTC, Chiquinquirá, 1982 (Versión del francés de Héctor Miguel Jara Cruz).

20 GUILLÉN MARTíNEZ, Fernando). Dice: “(...) Que se convirtió en un lugar común atribuir a la influencia inicial de la Iglesia la persistencia de los rasgos más arcaicos de la sociedad, sin percibir que el clero persiguió actuando después de 1887 con mayor virulencia como simple portavoz de los valores y de pautas sociales engendradas en el régimen hereditario de la encomienda y de la hacienda. Como un clero esencialmente "misionero" cumplidor de una Misión coactiva en beneficio del modelo social dominante y ejercido sobre la población. Fue una misión de relaciones públicas y propaganda, cuyos centros de decisión nunca residieron en el clero mismo internamente". GUILLÉN MARTínEZ, Fernando. El Poder Político en Colombia. Punta de lanza. Bogotá. 1979. p 487.

21 Las relaciones entre la Iglesia y el Estado se regularon por el Concordato de 1887, adicionado en 1891, y a la Iglesia se le otorgó inmenso poder. De nuevo se puso en sus manos el destino civil de las personas y a ella quedó encomendado el registro de nacimientos, matrimonios y muertes. Los cementerios quedaron bajo su control, el divorcio se suprimió y el matrimonio civil se dificultó y se convirtió en elemento de escarnio para quienes lo contrajeran. Se autorizó de nuevo la constitución de órdenes religiosas dentro del territorio nacional y a ellas se confirió la educación.

22 Hasta 1888 y durante casi todo el siglo XIX, la circunscripción electoral estaba integrada por Distritos Parroquiales, en los que el presbítero era un miembro fijo, junto a autoridades civiles como el alcalde 0 el juez, de los jurados o juntas escrutadoras. Registraduría Nacional del Estado Civil, Historia Electoral Colombiana, Bogotá, Regional. 1988. p. 139.

23 Gaceta de Santander. Bucaramanga, septiembre 30 de 1935. Número 5.754. circular del ministerio de gobierno sobre cédula electoral. Ministerio de Gobierno - Bogotá, septiembre 18 de 1935.

24 Explícitamente se planteaba no sólo que ser liberal era pecado sino también lo era apoyar candidatos que no le garantizaran a la iglesia la defensa de sus intereses. Por ejemplo, en mayo 7 de 1933, la prensa liberal denunciaba que el Arzobispo de Medellín Monseñor Manuel José Caicedo había instaurado como pecado votar por candidatos cuyas ideas religiosas fueran contrarias o desconocidas para la iglesia. CDIHR.-UIS. Vanguardia Liberal. p 3.Mayo 7 de 1933. 